\title{
Petrografia e geoquímica dos granulitos do Complexo Acaiaca, região Centro-Sudeste de Minas Gerais
}

\author{
(Petrography and geochemistry of the Acaiaca Complex granulites, \\ center-southeast portion of Minas Gerais)
}

\section{Edgar Batista de Medeiros Júnior}

Doutorando do Programa de PósGraduação em Evolução Crustal e Recursos Naturais Departamento de Geologia (DEGEO) Escola de Minas/UFOP E-mail: edgarjr@ymail.com

\section{Hanna Jordt Evangelista}

Professora do Departamento de Geologia (DEGEO) Escola de Minas/UFOP. E-mail: hanna@degeo.ufop.br

\section{Resumo}

O Complexo Acaiaca abrange uma região composta, predominantemente, por rochas de fácies granulito e essa região está localizada próximo à cidade de Acaiaca, Minas Gerais. O Complexo se estende por, no mínimo, 36 km na direção norte-sul e atinge cerca de $6 \mathrm{~km}$ de largura na porção central. Granulitos félsicos (biotita granulitos e charnockitos), granulitos máficos (piroxênio \pm hornblenda granulitos), granulitos ultramáficos (olivina-piroxênio granofels) e granulitos aluminosos (granada-sillimanita \pm cordierita granulitos e granada-ordierita-cianita granulitos) são litotipos encontrados nesse Complexo. Os granulitos félsicos são derivados de rochas de composição riolítica. Os máficos são derivados de rochas quimicamente semelhantes a basaltos de ambientes de arco de ilhas. Os granulitos aluminosos apresentam protólito sedimentar pelítico a grauvaquiano. O olivinapiroxênio granofels possui composição química semelhante a harzburgitos. As paragêneses minerais indicam metamorfismo de fácies granulito de pressão intermediária para formação das mesmas. Os gnaisses de fácies anfibolito encontrados na área do Complexo Acaiaca comumente apresentam microestruturas miloníticas e evidências de geração por retrometamorfismo a partir dos granulitos em zonas de cisalhamento.

Palavras-chave: Complexo Acaiaca, granulitos, geoquímica, metamorfismo de pressão intermediária.

\begin{abstract}
The Acaiaca Complex, located near the town of Acaiaca, Minas Gerais, is composed predominantly of granulite facies rocks. The Complex extends for at least $36 \mathrm{~km}$ in the $\mathrm{N}$-S direction and is about $6 \mathrm{~km}$ wide in the central area. Felsic (biotite granulites and charnockites), mafic (pyroxene \pm hornblende granulites), ultramafic (olivine-pyroxene granofels) and aluminous granulites are the main rock types. Felsic granulites are derived from rocks of rhyolitic composition. Mafic granulites are derived from rocks geochemically similar to island arc basalts. Aluminous granulites are derived from pelitic rocks and greywackes. The olivine-pyroxene granofels present a chemical composition similar to harzburgites. The mineral assemblages of granulites indicate an intermediatepressure granulite facies metamorphism for their formation. Metamorphic rocks of lower grade found in the area of the Acaiaca Complex commonly present
\end{abstract}


mylonitic microstructures and evidences of generation by retrometamorphism of the granulites in shear zones.

Keywords: Acaiaca Complex, granulites, geochemistry, intermediate-pressure metamorphism.

\section{Introdução}

O Complexo Acaiaca (Jordt-Evangelista, 1984, 1985 e Jordt-Evangelista \& Müller, 1986a, 1986b) situa-se na região centro-sudeste de Minas Gerais, mais especificamente nos municípios de Mariana, Acaiaca, Barra Longa e Diogo de Vasconcelos. Está inserido na Província Mantiqueira Setentrional (Almeida \& Hasui, 1984). As rochas desse Complexo são, predominantemente, granulitos, que se distribuem ao longo de uma área com algumas dezenas de quilômetros de extensão NS e de poucos quilômetros de largura, que é ladeada por terrenos com gnaisses de fácies anfibolito (Figura 1).

Embora conhecido de longa data, os estudos petrográficos até então desenvolvidos no Complexo Acaiaca (CA) limitaram-se a sua porção central (JordtEvangelista, 1984 e 1985). O presente trabalho teve como objetivo investigar a diversidade litológica do CA em toda a sua faixa de ocorrência, enfatizando a caracterização microestrutural e da composição mineralógica e geoquímica. Esses estudos visam a contribuir para o entendimento da constituição da Província Geotectônica Mantiqueira, composta, predominantemente, por gnaisses ortoderivados de fácies anfibolito médio na região em pauta, dentro da qual o CA, com constituição petrográfica diversificada e, predominantemente, de fácies granulito, representa uma unidade geológica particular.

\section{Materiais e métodos}

Os estudos petrográficos e microestruturais dos litotipos do CA se basearam na descrição de 213 lâminas delgadas de amostras provenientes de 128 pontos distribuídos conforme é representado na Figura 2. Para as análises químicas de rocha total, foram selecionadas 21 amostras de granulitos. As análises de elementos-traços foram realizadas via Espectrofotômetro de Emissão Atômica com Fonte Plasma (ICP-OES), no Laboratório de Geoquímica Ambiental do DEGEO-UFOP. As análises dos ele-

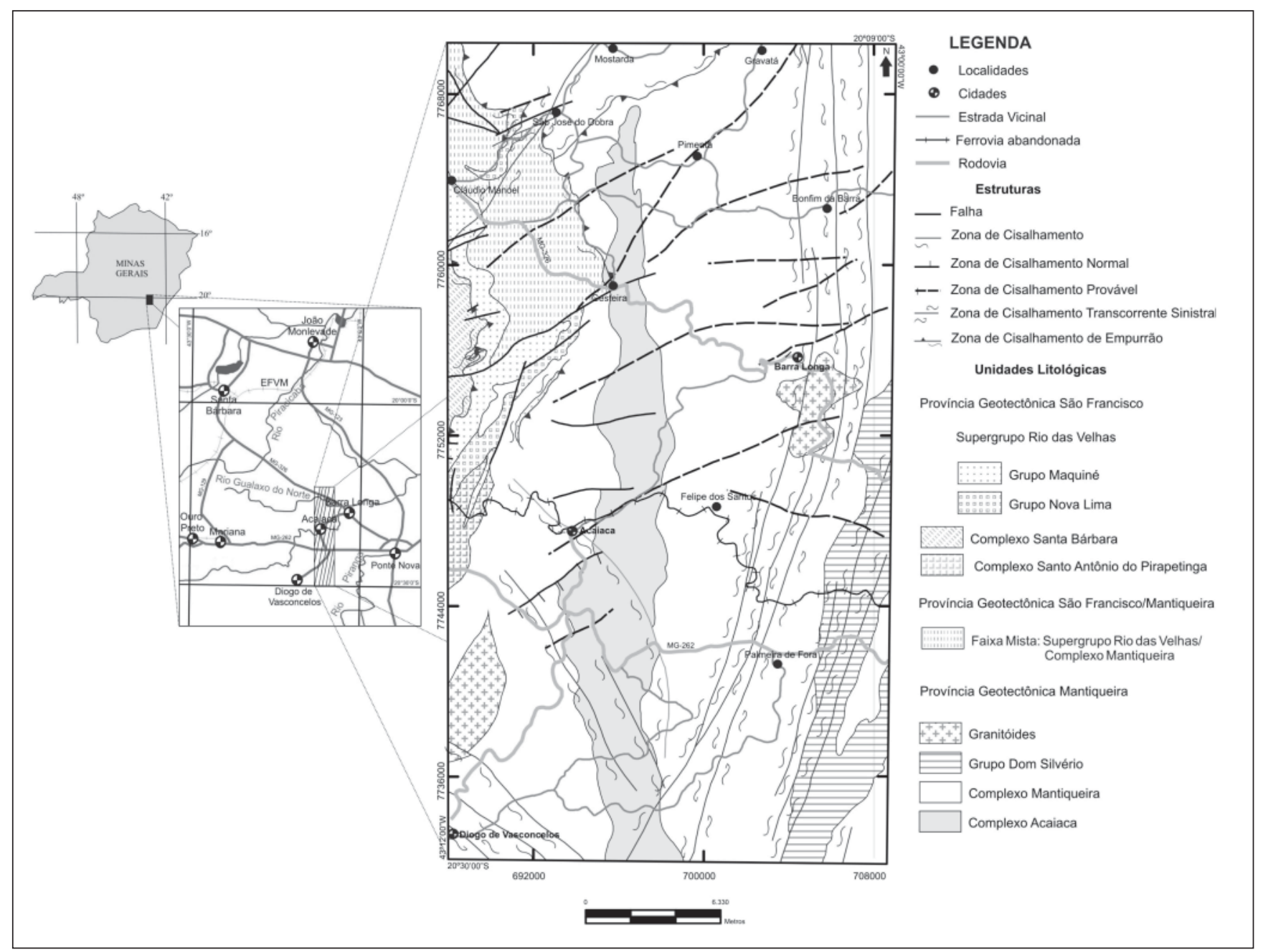

Figura 1 - Localização geográfica e mapa geológico do Complexo Acaiaca (Baltazar \& Raposo 1993). 
mentos maiores foram realizadas via Espectrômetro de Fluorescência de Raios X (FRX), no Laboratório de Preparação de Amostras para Geoquímica e Geocronologia (LOPAG) do DEGEO-UFOP.

\section{Petrografia}

A análise da distribuição espacial dos diferentes litotipos do Complexo Acaiaca é dificultada pelo acentuado grau de intemperismo que causa a obliteração dos contatos. Na Figura 2, observam-se os diversos pontos estudados em função dos litotipos encontrados e a faixa constituída, predominantemente, por rochas de fácies granulito. Essa área é maior do que aquela originalmente identificada por Jordt-Evangelista (1984) e também maior do que a área do Complexo no mapa de Baltazar e Raposo (1993) (Figura 1). Ela se estende por, no mínimo, 36 km na direção norte-sul e atinge cerca de $6 \mathrm{~km}$ de largura na porção central e torna-se, progressivamente, mais estreita para o norte e para o sul, ultrapassando os limites da região estudada.

Os granulitos que possuem paragêneses e composição química indicativas de protólito ígneo foram classificados como granulitos félsicos, máficos e ultramáficos. Os félsicos são biotita granulitos e charnockitos, os máficos são piroxênio \pm hornblenda granulitos e os ultramáficos são olivina-piroxênio granofels. Granulitos de protólito sedimentar pelítico foram denominados granulitos aluminosos. A composição modal de amostras representativas desses granulitos encontra-se na Tabela 1. Granulitos félsicos e máficos são, freqüentemente, bandados (Figura 3A), com alternância de bandas de espessura decimétrica a centimétrica. Na área do CA delimitada na Figura 2 também ocorrem gnaisses de fácies anfibolito, gabros, metagabros, anfibolitos, diabásios, quartzitos, cianita xistos, pegmatitos e metagranitos. Afloramentos que permitem identificar as relações de contato entre esses diversos tipos litológicos e os granulitos não foram encontrados, exceto no que se refere aos diabásios, que aparecem na forma de diques (Figura 3B), e aos pegmatitos, que ora cortam os granulitos e ora aparecem em contato difuso com os mesmos (Figura 3C). O estudo comparativo da triclinicidade de feldspatos potássicos dos pegmatitos que cortam os granulitos e dos pegmatitos que cortam os gnaisses de fácies anfibolito da região (Medeiros Júnior, 2009) mostra uma diferença no grau de triclinicidade entre os dois: o feldspato potássico dos pegmatitos associados aos granulitos tem baixa triclinicidade, próxima de zero, isto é, trata-se de ortoclásio, e o dos associados aos gnaisses tem tricliniciade bem maior, o que é característico de microclina. Portanto os pegmatitos dos granulitos foram cristalizados em temperaturas maiores do que os dos gnaisses, logo, podem tratar-se de pegmatitos gerados por anatexia durante o evento de fácies granulito.

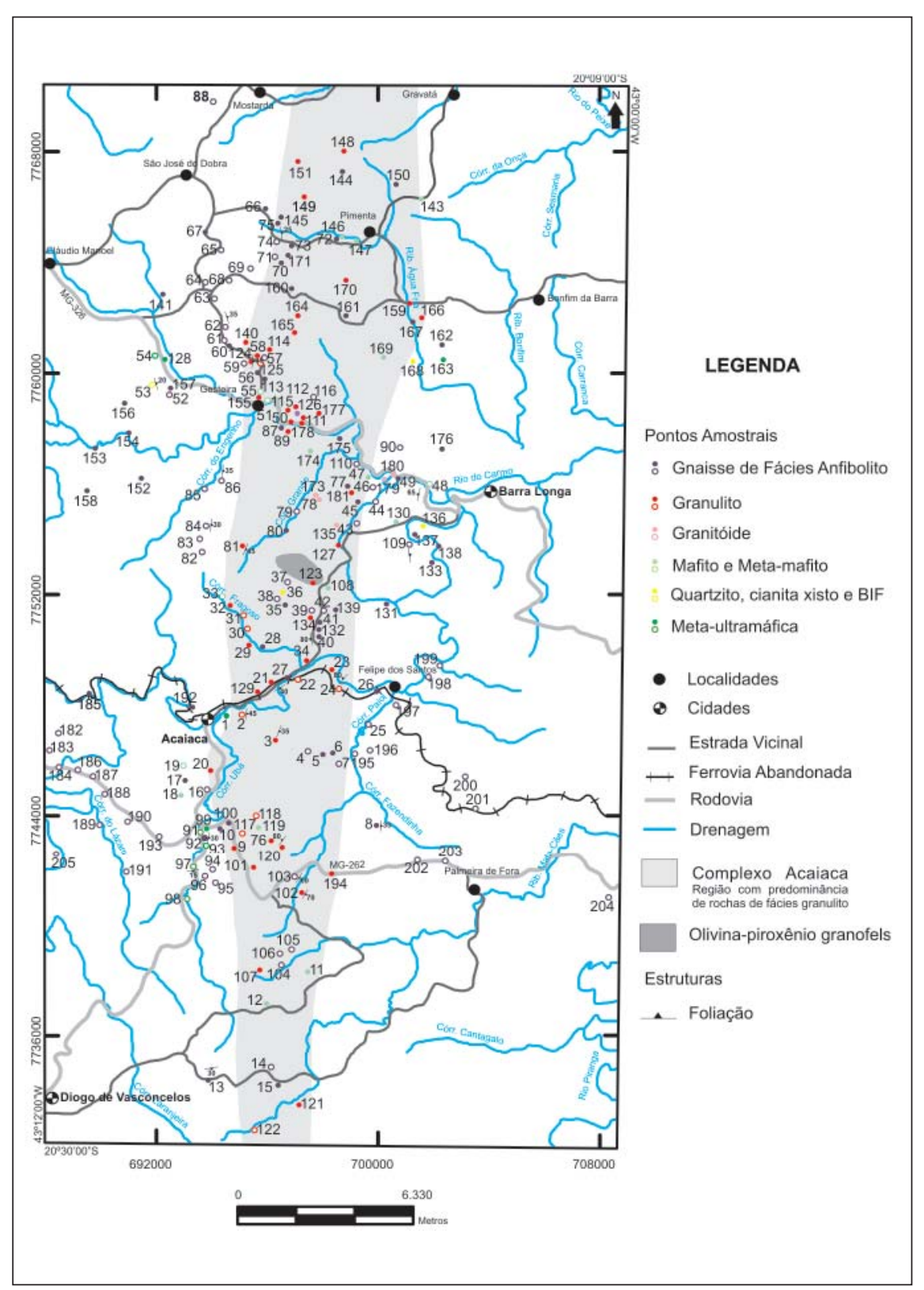

Figura 2 - Mapa de distribuição dos litotipos, com delimitação da faixa composta predominantemente por rochas de fácies granulito (Complexo Acaiaca). Nos pontos amostrais, os círculos vazios representam pontos sem lâminas delgadas e os cheios aqueles com lâminas delgadas. 
Petrografia e geoquímica dos granulitos do Complexo Acaiaca, região Centro-Sudeste de Minas Gerais Tabela 1 - Composição modal (em \% volume) dos granulitos do Complexo Acaiaca.

\begin{tabular}{|c|c|c|c|c|c|c|}
\hline \multirow{2}{*}{ Minerais } & \multicolumn{2}{|c|}{ Granulito félsico } & \multirow{2}{*}{$\begin{array}{c}\text { Granulitos } \\
\text { máfico }\end{array}$} & \multirow{2}{*}{$\begin{array}{l}\text { Olivina- } \\
\text { piroxênio } \\
\text { granofels }\end{array}$} & \multicolumn{2}{|c|}{ Granulito aluminoso* } \\
\hline & $\begin{array}{c}\text { Biotita } \\
\text { granulito }\end{array}$ & Charnockito & & & A & B \\
\hline Plagioclásio & $3-55$ & $5-52$ & $25-48$ & - & $22-40$ & $0-15$ \\
\hline Feldspato potássico & $0-50$ & $0-50$ & - & - & $0-20$ & - \\
\hline Biotita & $1-25$ & $0-25$ & $0-12$ & - & $10-25$ & $8-35$ \\
\hline Quartzo & $10-45$ & $15-45$ & $0-10$ & - & $13-25$ & $3-25$ \\
\hline Olivina & - & - & - & $25-30$ & - & - \\
\hline Ortopiroxênio & - & $1-5$ & $2-30$ & $43-50$ & - & - \\
\hline Clinopiroxênio & - & - & $5-25$ & - & - & - \\
\hline Hornblenda & $0-8$ & $0-20$ & $0-40$ & - & - & - \\
\hline Cummingtonita & - & - & $0-3$ & - & - & - \\
\hline Granada & $0-20$ & - & $0-10$ & - & $5-25$ & $0-20$ \\
\hline Ortoanfibólio & - & - & - & $4-8$ & - & - \\
\hline Cordierita & - & - & - & - & $0-10$ & $5-46$ \\
\hline Sillimanita & - & - & - & - & $5-10$ & - \\
\hline Cianita & - & - & - & - & - & $3-20$ \\
\hline Estaurolita & - & - & - & - & - & $0-4$ \\
\hline Talco & - & - & - & $2-3$ & - & - \\
\hline Mg-clorita & - & - & - & $3-5$ & - & $1-45$ \\
\hline Serpentina & - & - & - & 5 & $<1$ & - \\
\hline Apatita & $<1$ & $<1$ & $<1$ & - & $<1$ & $<1$ \\
\hline Zircão & $<1$ & $<1$ & - & - & $<1$ & $<1$ \\
\hline Monazita & $<1$ & - & - & - & $<1$ & $<1$ \\
\hline Opacos & $<$ & $<1$ & $<1-5$ & $3-8$ & $<1$ & $<1$ \\
\hline Muscovita & $<1$ & $<1$ & - & - & $<1$ & $<1$ \\
\hline Fe-Mg Clorita & $<1$ & $<1$ & - & - & $<1$ & - \\
\hline Epídoto & $<1$ & $<1$ & $<1$ & - & - & $<1$ \\
\hline Carbonato & - & $<1$ & $<1$ & $2-4$ & - & - \\
\hline
\end{tabular}

* A: granada-sillimanita \pm cordierita granulito; B: granada-cordierita-cianita granulito. 


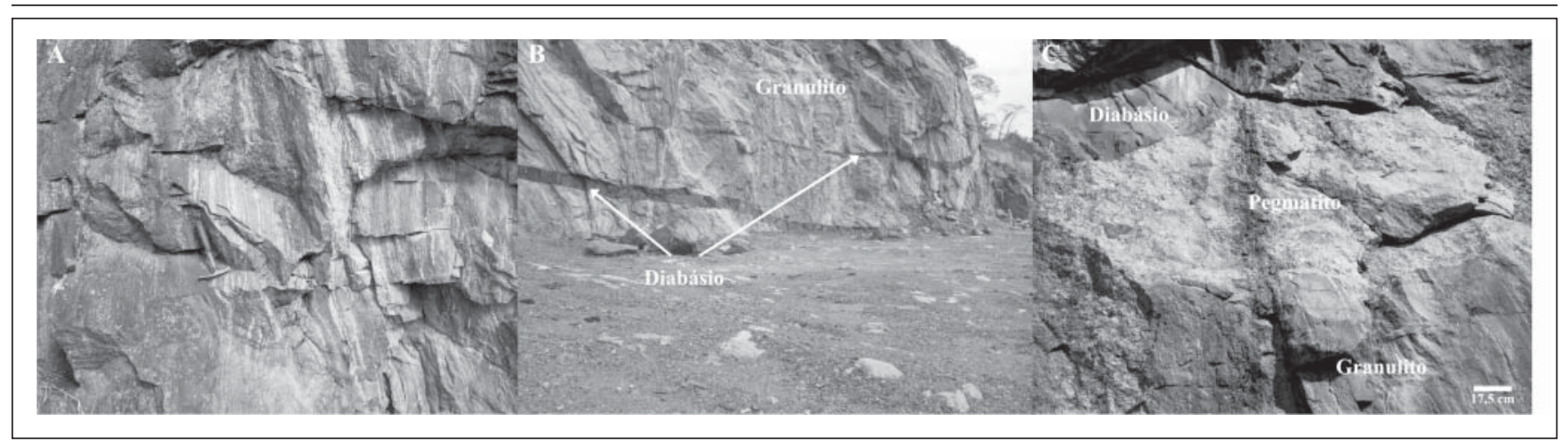

Figura 3 - Granulitos bandados encontrados na pedreira abandonada de Acaiaca (ponto 76). A: Granulito com intercalação de bandas félsicas e máficas verticalizadas. B: Diques de diabásio cortando os granulitos. C: Pegmatito que exibe contatos com granulito que variam de difuso a abrupto.

Os granulitos, comumente, possuem uma foliação milonítica paralela ao bandamento de direção NNE-SSW e mergulhos que variam de $35^{\circ}$ para ESE até subverticalizados. Esse paralelismo pode ser mais bem observado na transição de bandas máficas para félsicas, que se caracterizam por uma zona intermediária milonítica. Os gnaisses de fácies anfibolito encontrados na faixa de ocorrência do Complexo Acaiaca apresentam fortes evidências de milonitização, que são bem mais raras em gnaisses nas áreas adjacentes. A foliação gnáissica, que é paralela ao bandamento, possui direção preferencial semelhante ao bandamento dos granulitos, isto é, praticamente N-S e com mergulho variando de até $35^{\circ}$ para leste até $65^{\circ}$ para oeste.

\section{Granulitos félsicos}

Os granulitos félsicos são os litotipos de fácies granulito mais abundantes na região, possivelmente por representarem rochas mais resistentes ao intemperismo do que os outros granulitos. A paragênese principal é formada por biotita + plagioclásio + quartzo \pm feldspato potássico \pm granada \pm ortopiroxênio. Apesar de parte dos litotipos félsicos serem isentos de ortopiroxênio, os mesmos também pertencem à fácies granulito por conterem plagioclásio com antipertita e ortoclásio (e não microclina) e porque, comumente, ocorrem em bandas centimétricas a decimétricas, alternando-se com os granulitos máficos.
Apresentam textura inequigranular, que varia de granoblástica a granolepidoblática. Biotita é, comumente, castanhoavermelhada, o que sugere a presença de Ti na sua composição, conforme é comum nessa fácies. Inclusões de zircão, apatita e monazita geram halos pleocróicos. Plagioclásio ocorre como xenoblastos de 0,05 a $5 \mathrm{~mm}$ que podem apresentar exsolução de antipertita. Quartzo constitui grãos xenoblásticos de até $5 \mathrm{~mm}$ com forte extinção ondulante e que, freqüentemente, exibem microestrutura do tipo núcleo-manto. Ortoclásio ocorre sob a forma de xenoblastos de 0,05 a $4 \mathrm{~mm}$. Em amostras milonitizadas, encontra-se microclina, a qual deve ter-se originado a partir do ortoclásio em virtude da deformação. Granada constitui porfiroblastos de até $1 \mathrm{~cm}$, que contêm inclusões de quartzo, biotita e feldspatos. Ortopiroxênio ocorre como grãos subidioblásticos de até $0,2 \mathrm{~mm}$, que freqüentemente, estão, em contato com hornblenda de pleocroísmo castanho-amarelado, verde-escuro, verde-acastanhado.

\section{Granulitos máficos}

Os granulitos máficos representam o segundo grupo de granulitos mais abundante na região. A paragênese principal é formada por ortopiroxênio + clinopiroxênio + plagioclásio \pm hornblenda. Apresentam textura inequigranular granoblástica. Entretanto algumas amostras exibem bandamento formado pela alternância de camadas de plagioclásio e piroxênio ou pela inter- calação de bandas ricas em hornblenda e piroxênio. Plagioclásio ocorre como xenoblastos de 0,05 a 0,8 mm, que apresentam contatos interlobados a poligonizados. Hornblenda constitui grãos de pleocroísmo castanho-amarelado, verde-acastanhado a verde-escuro, que, freqüentemente, exibem zonamento de cor, caracterizados por núcleo de cor castanha e bordas em tons manchados de verde e castanho- escuro (Figura 4A). Ortopiroxênio é xenoblástico e mede de 0,05 a $1 \mathrm{~mm}$. Clinopiroxênio aparece subidioblástico a xenoblástico e com até $5 \mathrm{~mm}$. Quartzo é, praticamente, ausente nas amostra ricas em hornblenda, mas perfaz até $10 \%$ naquelas pobres nesse anfibólio. Biotita tem forte pleocroísmo de castanho-avermelhado a quase incolor. Hornblenda de pleocroísmo verdeclaro, verde-azulado a castanho-claro ocorre como produto da substituição marginal de hornblenda zonada de cor mais intensa e de piroxênio. Clinoanfibólio incolor da série cummingtonitagrunerita é resultado da substituição parcial ou total de ortopiroxênio. Granada é, comumente, xenoblástica, mas, se apresenta, parcialmente, euédrica, quando em contato com biotita. Pode ocorrer como corona em torno de ilmenita ou em intercrescimento simplectítico com esta. Ainda uma outra forma de ocorrência é representada por coronas de granada envolvendo grãos de plagioclásio, que estão em contato com piroxênios e hornblenda (Figura 4B). Essa microestrutura sugere que a granada presente nos granulitos máficos não pertence à paragênese de fácies granulito. 


\section{Olivina-piroxênio granofels}

A rocha ultramáfica é constituída, essencialmente, por olivina e ortopiroxênio, não sendo descrita por JordtEvangelista (1984) e nem por Baltazar e Raposo (1993), e é encontrada em afloramentos dispersos numa área de aproximadamente $2 \mathrm{~km}^{2}$ (Figura 2). Os blocos são, composicionalmente, homogêneos, em termos da distribuição da mineralogia, porém, localmente, apresentam talcificação e serpentinização incipiente. Na área de ocorrência, foram encontrados, também, granulitos máficos e metadiabásios. A não observação de contatos desses litotipos com a ultramáfica dificulta a interpretação da sua origem, se ígnea ou metamórfica. Nesse trabalho, o olivina-piroxênio granofels foi classificado como um tipo de granulito (e não um peridotito ígneo), já que está inserido no interior da faixa onde predominam litotipos de fácies granulito. O olivina-piroxênio granofels apresenta textura granoblástica a poiquiloblástica composta por grãos de olivina e ortopiroxênio, que podem chegar a 2,7 cm. Ortopiroxênio pode estar, parcialmente, substituído por carbonato, talco e ortoanfibólio. Em algumas amostras, observam-se diversas inclusões de olivina, que apresentam todas a mesma posição de extinção, isto é, parecem ser porções separadas de um mesmo grão, que foi parcialmente substituído por ortopiroxênio (Figura 4C). Nas porções mais retrometamorfizadas, a rocha ultramáfica é composta, basicamente, por talco, clorita, serpentina e antofilita.

\section{Granulitos aluminosos}

Os granulitos aluminosos possuem mineralogia típica de rochas metamórficas paraderivadas. A associação mineral principal é formada por um polimorfo de $\mathrm{Al}_{2} \mathrm{SiO}_{5}$ (sillimanita ou cianita), biotita, granada, plagioclásio e quartzo, podendo conter ortoclásio e cordierita. Verifica-se que as amostras com sillimanita não portam cianita e aquelas com cianita não possuem sillimanita. Os litotipos com cianita são granolepi- doblásticos, possuindo palhetas de biotita que exibem orientação preferencial. Aqueles com sillimanita apresentam textura inequigranular comumente granoblástica. Cianita é subidioblástica a idioblástica, em grãos de $0,1 \mathrm{~mm}$ a $1,5 \mathrm{~cm}$, freqüentemente, envolvidos por coronas de cordierita. Observa-se que diversas inclusões de cianita em grão maior de cordierita se extinguem todas simultaneamente, o que indica serem porções diferentes de um grão de cianita substituído parcialmente por cordierita. Sillimanita ocorre sob forma de fibrolita (Figura 4D), nas bordas de granada, feldspatos e cordierita e pode estar intercrescida com biotita. Nas amostras com sillimanita, cordierita é mais rara e ocorre como grãos de 0,2 a 1,5 mm (Figura 4D). As rochas que possuem cianita são caracterizadas por minerais que estão, parcial ou totalmente, substituídos por coronas de cordierita (Figuras 4E e 4F). Plagioclásio ocorre em grãos xenoblásticos de 0,1 a 2 mm de contatos, freqüentemente interlobados e que podem conter intercrescimento de quartzo mirmequítico e exibir exsolução de antipertita. Quartzo constitui grãos xenoblásticos de tamanho de 0,05 a $2,5 \mathrm{~mm}$. Pode formar microestrutura do tipo núcleo-manto e/ou possuir forte extinção ondulante. Feldspato potássico foi encontrado somente em amostras que portam sillimanita. Ocorre como grãos xenoblásticos de 0,05 a 1,5 mm, pertíticos, que apresentam mirmequita em suas bordas e, em algumas amostras, exibem maclas em grade incipientes. Biotita, freqüentemente, contém inclusões de rutilo, zircão e apatita. Nas amostras com cianita, o pleocroísmo varia de castanho a quase incolor e, nas amostras com sillimanita, o pleocroísmo é castanho-avermelhado a amarelo-pálido. Granada ocorre como porfiroblastos xenoblásticos a subidioblásticos de $0,1 \mathrm{~mm}$ a $1,2 \mathrm{~cm}$, que contêm inclusões de quartzo, biotita, minerais opacos e, mais raramente, de plagioclásio, estaurolita, cianita ou sillimanita. Mg-clorita é produto da substituição de cordierita. Estaurolita ocorre somente nos granulitos com cianita encontrados no ponto 129. Apresenta-se como grãos subidioblásticos a xenoblásticos de 0,05 a 0,6 mm inclusos em granada ou envolvidos por cordierita (Figura 4F).

\section{Geoquímica dos granulitos}

A Tabela 2 mostra os dados de geoquímica dos granulitos. Entre todos os granulitos, os félsicos são aqueles que apresentam os teores mais baixos de $\mathrm{Cr}$ (3,1 - 63,3 ppm), Ni (3,0 - 21,1 ppm) e V (6,6 - 57,2 ppm). Os teores de Ba (64,3 - 1256,0 ppm), Zr (22,2 - 210,9 ppm) e Th (0,7 - 10,2 ppm) são, relativamente, elevados, quando comparados aos dos outros granulitos. O teor de Th só é mais baixo que o dos granulitos aluminosos. O diagrama TAS (total álcalis $\times \mathrm{SiO}_{2}$ ) de Le Bas et al. (1986) (Figura 5A) mostra que os granulitos félsicos podem ser correlacionados a rochas ígneas de composição riolítica. O diagrama triangular AFM de Irvine \& Baragar (1971) (Figura 5B) mostra que três das amostras de granulitos félsicos plotam próximas do vértice $\mathrm{A}\left(\mathrm{Na}_{2} \mathrm{O}+\right.$ $\mathrm{K}_{2} \mathrm{O}$ ), isto é, têm composição compatível com diferenciados finais gerados por processos de cristalização fracionada de magmas de natureza calcioalcalina. O outro litotipo é compatível com os membros menos diferenciados da suíte. O diagrama de saturação em alumínio (Figura 5C) mostra que os granulitos félsicos são peraluminosos. Os granulitos aluminosos apresentam teores elevados de Th (5,9 - 25,1 ppm), Ва (222,1 1080,0 ppm), Zr (84,2 - 162,2 ppm) e V (59,0 - 192,8 ppm), quando comparados aos outros granulitos. Os teores de Co (36,4 - 70,7 ppm) são os mais baixos. Os teores de $\mathrm{Ni}$ (41,4 - 127,2 ppm) são mais baixos que os teores encontrados para os granulitos máficos (58,9 - 231,2 ppm) e para os olivina-piroxênio granofels (2159,0 - 2269,0 ppm), entretanto são mais altos que os teores encontrados para os granulitos félsicos (3,0 - 21,1 ppm). O diagrama de Moine (1969 in Fujimori, 1990) (Figura 5D) mostra que os granulitos aluminosos com sillimanita caem no campo reservado a grauvacas e aqueles com cianita, no campo reservado a folhelhos e rochas argilo-carbonatadas. Isso confirma a origem desses litotipos a partir de rochas sedimentares de origem detrítica. O diagrama discriminante de Roser e Korsch (1986) (Figura 5E) indica que o protólito desses granulitos 


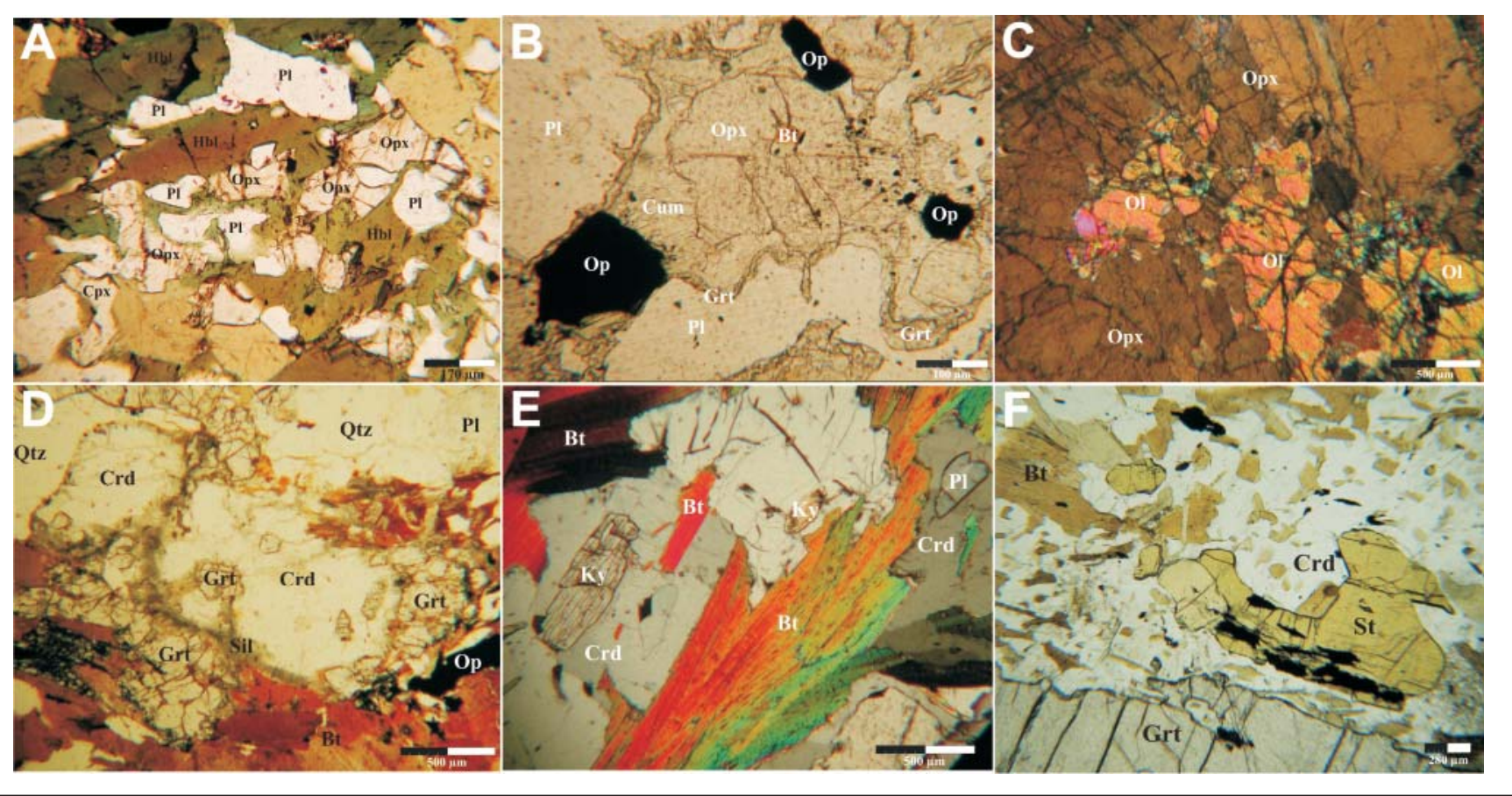

Figura 4 - Fotomicrografias de granulitos do Complexo Acaiaca. A: Granulito máfico com Hbl mostrando zonamento de cor, núcleo castanho e borda esverdeada (LPP). B: Granulito máfico com Opx parcialmente substituído por Cum e com Grt desenvolvida entre Opx e PI (LPP). C: Olivina-piroxênio granofels exibindo grãos de Ol com a mesma orientação cristalográfica dentro de Opx (LPX). D: Granulito aluminoso mostrando Crd com Sil e Bt em suas bordas (LPP). E: Granulito aluminoso com Ky, Bt e PI envolvidos por Crd (LPX). F: Granulito aluminoso mostrando Bt, Grt e St envolvidos por Crd (LPP). Legenda: clinopiroxênio (Cpx), ortopiroxênio (Opx), plagioclásio (PI), hornblenda (Hbl), cummingtonita (Cum), granada (Grt), opacos (Op), olivina (OI), sillimanita (Sil), biotita (Bt), quartzo (Qtz), cordierita (Crd), cianita (Ky) e estaurolita (St). LPP: luz polarizada plana; LPX: luz polarizada cruzada.

pode ter sido gerado em um ambiente de arco de ilhas. Os granulitos máficos são caracterizados por teores relativamente baixos de $\mathrm{Zr}$ (10,9-73 ppm) e Th (até 2,1 ppm). Os teores de $\mathrm{V}$ (193,3 - 373,0 ppm) e Cu (90,7 - 390,6 ppm) são os mais altos entre todos os granulitos estudados. O diagrama TAS (total álcalis $x \mathrm{SiO}_{2}$ ) de Le Bas et al. (1986) (Figura 5A) mostra que os granulitos máficos podem ser correlacionados a basaltos e andesitos basálticos subalcalinos. O diagrama triangular AFM de Irvine e Baragar (1971) (Figura 5B) evidencia que caem no campo da suíte tholeiítica. O diagrama triangular de Mullen (1983) (Figura 5F) indica um ambiente de arco de ilhas para o protólito dos granulitos máficos. O olivina-piroxênio granofels apresenta composição mineralógica semelhante a de harzburgitos, porém a sua associação espacial com granulitos máficos sugere que se trata de um granulito ultramáfico. A química dessa rocha mostra um elevado conteúdo de $\mathrm{MgO}$ (em torno de $38 \%$ ) e um conteúdo inexpressivo de $\mathrm{CaO}(0,09$ - 0,12 \%). Os teores de Ni (2159 - 2269 ppm) e Cr (3531 - 4176 ppm) são os mais elevados entre todos os granulitos estudados, com valores típicos de rochas ultramáficas. Os diagramas de $\mathrm{Cr} \mathrm{x}$ $\mathrm{TiO}_{2}$ (Figura 5G) e $\mathrm{Ni} \mathrm{x} \mathrm{TiO}_{2}$ (Figura 5H) de Hallberg (1985) indicam que essas rochas apresentam composição similar a komatiítos cumuláticos.

\section{Metamorfismo do Complexo Acaiaca: discussão e conclusões}

No Complexo Acaiaca predominam rochas geradas por metamorfismo de fácies granulito. Um evento retrometamórfico posterior, possivelmente relacionado à exumação do Complexo Acaiaca, transformou parte dos granulitos em gnaisses de fácies anfibolito.

Nos granulitos félsicos, derivados de rochas de composição riolítica e caracterizados pela paragênese plagioclásio + quartzo + granada + biotita \pm feldspato potássico \pm ortopiroxênio, o metamorfismo de fácies granulito é marcado pela ocorrência de ortopiroxênio, ortoclásio e plagioclásio com antipertita. Os granulitos máficos, derivados de rochas de composição basáltica, são compostos pela paragênese ortopiroxênio + clinopiroxênio + hornblenda + plagioclásio, típica de fácies granulito. Segundo De Ward (1965), que dividiu a fácies granulito em subfácies de baixa e alta pressão, a paragênese é característica de granulitos de pressão relativamente baixa. Os granulitos máficos do Complexo Acaiaca podem ser caracterizados como rochas de fácies granulito de condições de pressão baixa a intermediária, pois durante os estudos geotermobarométricos realizados por Medeiros Júnior (2009) 
Petrografia e geoquímica dos granulitos do Complexo Acaiaca, região Centro-Sudeste de Minas Gerais

Tabela 2 - Dados de geoquímica dos granulitos com elementos maiores obtidos via FRX e elementos-traços obtidos via ICP-OES.

\begin{tabular}{|c|c|c|c|c|c|c|c|c|c|c|c|c|c|}
\hline \multicolumn{14}{|c|}{ Elementos maiores e menores ( $\%$ peso) } \\
\hline Amostra & Litotipo & $\mathrm{SiO}_{2}$ & $\mathrm{Al}_{2} \mathrm{O}_{3}$ & $\mathrm{CaO}$ & $\mathrm{Na}_{2} \mathrm{O}$ & $\mathrm{FeOt}^{*}$ & $\mathrm{MgO}$ & MnO & $\mathrm{K}_{2} \mathrm{O}$ & $\mathrm{TiO}_{2}$ & $\mathrm{P}_{2} \mathrm{O}_{5}$ & PPC* $^{*}$ & Total \\
\hline PAC-89 & \multirow{4}{*}{$\begin{array}{c}\text { Granada-sillimanita } \\
\pm \text { cordierita granulito }\end{array}$} & 58,53 & 17,19 & 2,26 & 3,38 & 9,72 & 3,11 & 0,3 & 2,43 & 0,94 & 0,05 & 0,4 & 98,3 \\
\hline PAC-101 & & 64,36 & 16,72 & 1,74 & 2,64 & 6,72 & 2,7 & 0,08 & 2,88 & 0,75 & 0,07 & 0,3 & 98,96 \\
\hline PAC-120 & & 76,86 & 14,35 & 2,1 & 3,71 & 2,37 & 0,84 & 0,05 & 2,76 & 0,29 & 0,06 & 0,46 & 100,1 \\
\hline PAC-127 & & 65,01 & 15,66 & 2,07 & 2,84 & 6,91 & 2,98 & 0,18 & 1,86 & 0,76 & 0,1 & 0,9 & 99,26 \\
\hline PAC-111 & \multirow{4}{*}{$\begin{array}{c}\text { Granada-cordierita- } \\
\text { cianita granulito }\end{array}$} & 54,35 & 20,05 & 0,8 & 0,7 & 6,13 & 9,92 & 0,06 & 4,03 & 0,96 & 0,19 & 2,75 & 99,94 \\
\hline PAC-112 & & 49,85 & 21,56 & 1,4 & 1,6 & 5,79 & 11,51 & 0,04 & 4,6 & 0,88 & 0,18 & 2,29 & 99,69 \\
\hline PAC-126 & & 60,92 & 17,77 & 0,46 & 0,45 & 4,77 & 8,87 & 0,05 & 2,92 & 0,8 & 0,17 & 2,1 & 99,27 \\
\hline PAC-129 & & 50,03 & 19,72 & 0,25 & 0,32 & 7,94 & 11,02 & 0,06 & 4,97 & 1,27 & 0,2 & 2,64 & 98,41 \\
\hline PAC-20C & \multirow{4}{*}{ Granulito félsico } & 74,72 & 13,81 & 1,58 & 3,76 & 1,41 & 0,7 & 0,03 & 4,03 & 0,16 & 0,04 & 0,41 & 100,65 \\
\hline PAC-76B & & 80,47 & 12,38 & 3,74 & 3,19 & 0,22 & 0,02 & 0,01 & 0,44 & 0,03 & 0,02 & 0,42 & 100,94 \\
\hline PAC-76E & & 77,59 & 12,49 & 1,43 & 2,7 & 0,85 & 0,19 & 0,04 & 4,66 & 0,04 & 0,05 & 0,34 & 100,37 \\
\hline PAC-76N & & 76,17 & 11,5 & 2,29 & 2,73 & 4,09 & 1,11 & 0,15 & 0,97 & 0,22 & 0,03 & 0,41 & 99,67 \\
\hline PAC-23A & \multirow{7}{*}{ Granulito máfico } & 47,88 & 13,21 & 11,28 & 2,7 & 13,72 & 6,73 & 0,22 & 0,51 & 1,18 & 0,11 & 0,3 & 97,84 \\
\hline PAC-32A & & 50,28 & 13,54 & 12,01 & 1,89 & 11,9 & 7,43 & 0,21 & 0,23 & 0,97 & 0,09 & 0,4 & 98,96 \\
\hline PAC-58A & & 50,57 & 12,91 & 10,01 & 2,24 & 14,22 & 5,62 & 0,22 & 0,53 & 1,59 & 0,15 & 0,03 & 98,09 \\
\hline PAC-76J1 & & 50,54 & 16,14 & 14,03 & 1,61 & 6,76 & 9,53 & 0,14 & 0,47 & 0,42 & 0,06 & 0,3 & 99,99 \\
\hline PAC-76J3 & & 52,89 & 15,14 & 8,98 & 2,41 & 10,06 & 6,85 & 0,17 & 0,79 & 0,88 & 0,11 & 0,35 & 98,62 \\
\hline PAC-114C & & 49,27 & 16,88 & 10,82 & 2,45 & 13,19 & 3,92 & 0,19 & 0,28 & 1,47 & 0,13 & 0,17 & 98,78 \\
\hline PAC-121 & & 50,08 & 13,74 & 10,82 & 2,39 & 12,9 & 6,69 & 0,23 & 0,27 & 0,99 & 0,09 & 0,28 & 98,48 \\
\hline PAC-123M & \multirow{2}{*}{$\begin{array}{l}\text { Olivina-piroxênio } \\
\text { granofels }\end{array}$} & 43,9 & 1,45 & 0,09 & 0,18 & 10,48 & 35,55 & 0,1 & 0,02 & 0,1 & 0,03 & 5,47 & 97,37 \\
\hline PAC-123N & & 46,83 & 2,12 & 0,12 & 0,03 & 9,98 & 35,47 & 0,09 & 0,01 & 0,12 & 0,04 & 1,97 & 96,77 \\
\hline
\end{tabular}

\begin{tabular}{|c|c|c|c|c|c|c|c|c|c|c|c|c|c|c|}
\hline \multicolumn{15}{|c|}{ Elementos traços (ppm) } \\
\hline Amostra & Rocha & $\mathrm{Ba}$ & $\mathrm{Cr}$ & Co & $\mathrm{Cu}$ & $\mathrm{Li}$ & $\mathrm{Ni}$ & Sc & $\mathrm{Sr}$ & Th & v & $\mathrm{Y}$ & $\mathrm{Zn}$ & $\mathrm{Zr}$ \\
\hline PAC-111 & \multirow{4}{*}{$\begin{array}{l}\text { Granada-cordierita- } \\
\text { cianita granulito }\end{array}$} & 908,0 & 200,1 & 68,9 & 11,5 & 22,5 & 48,1 & 14,6 & 364,9 & 5,9 & 192,8 & 44,3 & 121,5 & 73,8 \\
\hline PAC-112 & & 1080,0 & 101,1 & 70,7 & 4,5 & 15,9 & 42,4 & 11,6 & 347,7 & 10,8 & 155,0 & 18,7 & 69,1 & 112,6 \\
\hline PAC-126 & & 910,0 & 32,1 & 62,8 & 10,2 & 12,5 & 17,0 & 3,7 & 319,8 & 10,2 & 59,0 & 20,3 & 26,2 & 114,6 \\
\hline PAC-129 & & 438,7 & 134,6 & 57,3 & 28,7 & 23,5 & 54,2 & 9,9 & 212,7 & 10,4 & 156,9 & 16,6 & 91,6 & 84,2 \\
\hline PAC-89 & \multirow{4}{*}{$\begin{array}{l}\text { Granada-sillimanita } \\
\pm \text { cordierita granulito }\end{array}$} & 342,9 & 127,7 & 47,9 & $<L Q$ & 64,3 & 69,6 & 8,3 & 42,2 & 18,3 & 160,3 & 13,0 & 59,9 & 109,7 \\
\hline PAC-101 & & 312,7 & 82,2 & 36,4 & 4,7 & 44,4 & 46,5 & 7,4 & 114,0 & 20,2 & 145,6 & 12,5 & 43,5 & 120,8 \\
\hline PAC-120 & & 222,1 & 75,6 & 48,1 & 1,9 & 70,8 & 41,4 & 6,4 & 25,1 & 18,8 & 117,9 & 13,8 & 32,4 & 76,2 \\
\hline PAC-127 & & 407,1 & 225,1 & 59,0 & $<\mathrm{LQ}$ & 55,1 & 127,2 & 12,5 & 4,1 & 25,1 & 162,5 & 13,5 & 83,7 & 162,2 \\
\hline PAC-20C & \multirow{4}{*}{ Granulito félsico } & 803,0 & 5,9 & 58,5 & 0,7 & 7,8 & 6,2 & 2,2 & 196,0 & 10,2 & 20,2 & 16,3 & 24,6 & 59,4 \\
\hline PAC-76B & & 64,3 & 3,1 & 103,6 & 3,0 & 19,3 & 4,2 & 0,6 & 145,4 & 0,7 & 6,6 & 0,5 & 3,4 & 22,2 \\
\hline PAC-76N & & 182,6 & 63,3 & 68,0 & 12,6 & 16,5 & 21,1 & 11,1 & 199,8 & 1,0 & 57,2 & 68,1 & 40,6 & 210,9 \\
\hline PAC-76E & & 1256,0 & 5,8 & 96,0 & 1,1 & 9,8 & 3,0 & 2,9 & 254,3 & 3,5 & 7,6 & 24,8 & 7,2 & 140,8 \\
\hline PAC-23A & \multirow{7}{*}{ Granulito máfico } & 968,0 & 111,2 & 79,3 & 90,7 & 7,7 & 97,7 & 25,3 & 139,9 & $<\mathrm{LQ}$ & 351,2 & 28,2 & 120,7 & 10,9 \\
\hline PAC-32A & & 64,3 & 129,1 & 77,7 & 142,1 & 4,7 & 92,0 & 25,3 & 126,7 & 0,5 & 295,5 & 16,2 & 101,3 & 11,7 \\
\hline PAC-58A & & 93,5 & 106,8 & 90,8 & 254,4 & 3,0 & 83,4 & 20,5 & 153,4 & 1,7 & 373,0 & 23,6 & 133,9 & 42,5 \\
\hline PAC-76J1 & & 45,5 & 480,9 & 52,6 & 132,9 & 11,9 & 201,4 & 21,2 & 99,2 & 0,5 & 193,3 & 7,6 & 62,4 & 13,1 \\
\hline PAC-76J3 & & 264,6 & 401,8 & 72,8 & 390,6 & 12,2 & 231,2 & 16,6 & 154,3 & 2,1 & 220,4 & 16,5 & 168,1 & 73,0 \\
\hline PAC-114C & & 47,9 & 48,1 & 76,3 & 124,6 & 5,2 & 58,9 & 18,0 & 145,7 & 0,5 & 360,7 & 23,0 & 117,1 & 14,9 \\
\hline PAC-121 & & 21,7 & 77,8 & 73,4 & 133,0 & 7,8 & 75,5 & 24,7 & 92,5 & $<\mathrm{LQ}$ & 333,6 & 20,2 & 96,9 & 13,1 \\
\hline PAC-123M & \multirow{2}{*}{$\begin{array}{l}\text { Olivina-piroxênio } \\
\text { granofels }\end{array}$} & 3,5 & 4176,0 & 127,6 & 5,7 & 1,8 & 2269,0 & 5,5 & 1,4 & $<\mathrm{LQ}$ & 41,0 & 1,4 & 115,9 & $<\mathrm{LQ}$ \\
\hline PAC-123N & & 5,2 & 3531,0 & 117,9 & 11,5 & 1,4 & 2159,0 & 5,1 & 1,6 & $<\mathrm{LQ}$ & 44,4 & 2,3 & 103,0 & 4,0 \\
\hline \multicolumn{2}{|c|}{ Limite de detecção (LQ) } & 0,001 & 0,011 & 0,007 & 0,006 & 0,003 & 0,016 & 0,02 & 0,0009 & 0,0009 & 0,016 & 0,099 & 0,027 & 0,019 \\
\hline
\end{tabular}

*PPC é a perda por calcinação; FeOt indica ferro total calculado como $\mathrm{Fe}^{2+}$.

226 REM: R. Esc. Minas, Ouro Preto, 63(2): 219-228, abr. jun. 2010 




Figura 5 - Diagramas para caracterização química dos granulitos. A: TAS (total álcalis $x \mathrm{SiO}_{2}$ ) de Le Bas et al. (1989) e com a divisão de séries alcalinas e subalcalinas segundo Irvine e Baragar (1971). B: Diagrama triangular AFM segundo Irvine e Baragar (1971). C: Diagrama que mede aluminosidade da rocha por meio dos índices de Shand (1963) e segundo os campos de Maniar \& Piccoli (1989). D: Diagrama de Moine para rochas sedimentares detríticas (1969 in Fujimori, 1990). E: Diagrama log $\left(\mathrm{K}_{2} \mathrm{O} / \mathrm{Na}_{2} \mathrm{O}\right)$ versus $\mathrm{SiO}_{2}$ de Roser e Korsch (1986). F: Diagrama triangular de Mullen (1983). G: Diagrama $\mathrm{Cr} \times \mathrm{TiO}_{2}$ de Hallberg (1985). H: Diagrama $\mathrm{Ni}^{x} \mathrm{TiO}_{2}$ de Hallberg (1985). Nas figuras A, $\mathrm{B}, \mathrm{C}$ e F, os campos tracejados mostram onde se concentram as amostras analisadas.

nesses litotipos, foram obtidos valores de pressão em torno de 6,5 kbar. De acordo com De Ward (1965), pressões mais altas são marcadas por paragêneses que contêm granada. Embora granada apareça nos granulitos máficos do Complexo Acaiaca, há evidências microestruturais de ser secundária, resultante do evento retrometamórfico de fácies anfibolito, tal como biotita, cummingtonita e hornblenda verde-azulada. O olivinapiroxênio granofels é composto pela paragênese principal dada por olivina + ortopiroxênio. De acordo com Bucher e
Frey (1994), rochas metamórficas ultramáficas compostas por essa paragênese podem ser geradas a partir de $670^{\circ} \mathrm{C}$, independente das condições de pressão. Verifica-se que a paragênese olivina + ortopiroxênio apresenta um campo de estabilidade que é compatível com as associações minerais encontradas nos outros granulitos do Complexo Acaiaca. A química dos granulitos ultramáficos permite correlacioná-los a harzburgitos. O evento retrometamórfico é evidenciado nessas rochas pela formação de antofilita, serpentinas, carbonatos e talco.
Os granulitos aluminosos apresentam mineralogia e química compatível com rochas derivadas de protólito sedimentar do tipo folhelho e grauvaca. São constituídos por dois litotipos principais. O primeiro é composto por granada + biotita + sillimanita + plagioclásio + quartzo \pm feldspato potássico \pm cordierita e o segundo, por biotita + cianita + plagioclásio + quartzo + cordierita \pm granada \pm estaurolita. A associação mineral do primeiro litotipo mostra-se texturalmente em equilíbrio e, de acordo com Lee e Holdaway (1977), indica 
recristalização sob condições do início da fácies granulito, sob temperaturas que variam de $690^{\circ}$ a $710^{\circ} \mathrm{C}$, condições de pressão entre 4 e 5,7 kbar e $\mathrm{XH}_{2} \mathrm{O}$ de 0,2 a 0,5 . White et al. (2007) evidencia, que essa paragênese pode indicar temperaturas mais altas e condições de pressão de até 8 kbar. Estudos geotermobarométricos, desenvolvidos por Medeiros Júnior (2009), corroboram isso, pois foram obtidas temperaturas entre $715^{\circ} \mathrm{C}$ e $732^{\circ} \mathrm{C}$ e pressões entre 6,4 e $8,4 \mathrm{kbar}$ para essas rochas. $\mathrm{O}$ segundo litotipo apresenta microestruturas não equilibradas como simplectitas e coronas. Nesse, os minerais podem ser agrupados em duas paragêneses distintas: estaurolita + cianita + plagioclásio + biotita + quartzo (mais antiga, de fácies anfibolito de média a alta pressão) e cordierita + granada + sillimanita + plagioclásio + biotita + quartzo (mais nova, de fácies granulito de baixa a média pressão).

A partir da análise das associações minerais que constituem os granulitos do Complexo Acaiaca, pode-se afirmar que essas rochas foram geradas em fácies granulito sob condições de pressão intermediária. A ocorrência de zonas de cisalhamento, granulitos milonitizados e/ou com bandamento verticalizado sugerem que, através de falhas de empurrão com direção NS e vergência para oeste, foi possível a ascensão do Complexo Acaiaca de níveis crustais profundos até níveis mais rasos constituídos pelos terrenos gnáissicos, conforme sugerido por Jordt-Evangelista \& Müller (1986a). Durante este processo parte das rochas foi gnaissificada e, no caso de acesso de fluidos aquosos, houve transformações retrometamórficas.

\section{Agradecimentos}

Nosso agradecimento à CAPES (Coordenação de Aperfeiçoamento de Pessoal de Nível Superior) pela bolsa de mestrado ao primeiro autor e ao revisor do artigo pelas sugestões.

\section{Referências bibliográficas}

ALMEIDA, F. F. M., HASUI, Y. O précambriano do Brazil. São Paulo: Edgard Blücher,1984. 378p.

BALTAZAR, O. F., RAPOSO, F. O. Programa levantamentos geológicos básicos do Brasil. Folha Mariana (SF.23-X-B-I). Estado de Minas Gerais. Escala: 1:100.000. Rio de Janeiro: CPRM, 1993. p.17-93.

BUCHER, K., FREY, M. Petrogenesis of metamorphic rocks. (6. ed.) Berlim: Springer, 1994. 318p.

DE WARD, D. A proposed subdivision of the granulite facies. American Journal of Science, v. 263, n. 4, p. 55-461, 1965.

FUJIMORI, S. Composição química de rochas e suas aplicações. Salvador: Centro Editorial e Didático da UFBA, 1990. 306p.

HALLBERG, J. A. Geology and mineral deposits of the LeonoraLaverton area, Northeastern Yilgarn Block, Western Australia. Western Australia: Hesperian Press, 1985. 140p.

IRVINE, T. N., BARAGAR, W.R.A. A guide to the chemical classification of the common volcanic rocks. Canadian Journal of Earth Sciences, v. 8, p. 523-548, 1971.

J OR D T-E VA N G E L IS TA, H . Petrologische untersuchungen im Gebiete zwischen Mariana und Ponte Nova, Minas Gerais, Brasilien. Alemanha: Universidade Técnica de Clausthal, 1984. 183p. (Tese de doutorado).

J OR D T-E VA N G E L IS TA, H . Petrologia de fases, geotermometria e geobarometria do Complexo Granulítico de Acaiaca, Sudeste do Quadrilátero Ferrífero, MG. In: SIMPÓSIO DE GEOLOGIA DE MINAS GERAIS, 3. Anais... Belo Horizonte: SBG, 1985. p. 165-178.

JORDT-EVANGELISTA, H., MULLER, G. Petrology of a transition zone between the Archean Craton and the Coast Belt, SE of the Iron Quadrangle, Brazil. Chemie der Erde, v. 45, p. 129-145, 1986a.
JORDT-EVANGELISTA, H., MULLER, G. Petrologia da Zona de Transição entre o Cráton do São Francisco e o Cinturão Móvel Costeiro na Região Sudeste do Quadrilátero Ferrífero, MG. In: CONGRESSO BRASILEIRO DE GEOLOGIA, 34. Anais... Goiânia, 1986b. p.1471-1479.

LE BAS, M. J. et al. A chemical classification of volcanic rocks based on the total alkali-silica diagram. Journal of Petrology, v. 27, n. 3, p. 745-750, 1986.

LEE, S. M., HOLDAWAY, M. S. Significance of Fe-Mg cordierite stability relations on temperature, pressure and water pressure in cordierite granulites. Geophysical Monograph, v. 20, p. 79-94, 1977.

MANIAR, P. D., PICCOLI, P. M. Tectonic discrimination of granitoids. Geological Society of America Bulletin, v. 101, p. 635-643, 1989.

MEDEIROS JÚNIOR, E. B. Petrogênese do Complexo Acaiaca, MG. Ouro Preto: Universidade Federal de Ouro Preto, 2009. 101p. (Dissertação de Mestrado).

MULlEN, E. D. $\mathrm{MnO} / \mathrm{TiO}_{2} / \mathrm{P}_{2} \mathrm{O}_{5}$ : a minor element discriminant for basaltic rocks of oceanic enviroments and its implications for petrogenesis. Earth and Planetary Science Letters, v. 62, p. 53-62, 1983.

ROSER, B. P., KORSCH, R. J. Determination of tectonic setting of sandstone-mudstone suites using $\mathrm{SiO}_{2}$ content and $\mathrm{K}_{2} \mathrm{O} / \mathrm{Na}_{2} \mathrm{O}$ ratio. Journal of Geology, v. 94, p. 635650, 1986.

SHAND, S. J. Rocks of the Mid-Atlantic Ridge. Journal of Geology, v. 57, p. 89-92, 1949.

WHITE, R. W., POWELL, R., HOLLAND, T. J. B. Progress relating to calculation of partial melting equilibria for metapelites. Journal of Metamorphic Geology, v. 25, p.511-527, 2007.

\section{Artigo recebido em 25/03/2009 e} aprovado em 18/11/2009. 